\title{
Medical care and long-term treatment of patients with schizophrenia: ethical concerns
}

\author{
Frederico Simões do Couto \\ From $1^{\text {st }}$ International Congress on Neurobiology and Clinical Psychopharmacology and European \\ Psychiatric Association Conference on Treatment Guidance \\ Thessaloniki, Greece. 19-22 November 2009
}

Despite the improvement in mental health care that has occurred in the last decades, the mortality risk in patients with schizophrenia has not been changed, and there was even an increase in the mortality of these patients when compared to the general population. The main causes for this increased mortality are somatic diseases, especially diabetes, hypercholesterolemia, hypertrygliceridemia, cardiovascular diseases (including arterial hypertension), obesity, HIV infection/AIDS, hepatitis C and osteoporosis [1]. The link between second generation antipsychotics and cardiovascular risk factors has raised questions on their overall safety, and these concerns are even more important if patients are on compulsory treatment. Furthermore, at least half of patients suffering from schizophrenia have one comorbidity not diagnosed or wrongly diagnosed [2]. In a sample of 476 community patients suffering from schizophrenia, we found rates of diagnosed hypertension of $6,9 \%$, hypercholesterolemia of $9,0 \%$, hypertrigliceridemia of $6,3 \%$, and diabetes of $4,2 \%$. Not only these figures are lower than in other large studies, but also apparently only 12 to $30 \%$ of the patients presenting these disorders were being treated for these conditions [3]. Barriers to recognition and management of physical diseases in patients with schizophrenia are related both to health care providers and to patient/disease. Acute admission could be a target for the screening and treatment of these disorders, and we tried to find a screening protocol for this situation. Acutely ill patients have higher rates of infections and liver abnormalities, but lower rates of hypercholesterolemia [4]. In our sample more than $80 \%$ of patients with schizophrenia are retired or unemployed. Resources are scarce, and their allocation

Neuroscience Department of the Institute of Molecular Medicine, Lisbon, and Department of Psychiatry, Hospital de Santa Maria and Faculty of Medicine of Lisbon, Portugal to these patients can prevent the access of people suffering from other disorders to the care they need.

Published: 22 April 2010

\section{References}

1. Saha $S$, et al: A systematic review of mortality in schizophrenia: is the differential mortality gap worsening over time? Arch Gen Psychiatry 2007, 64(10):1123-31.

2. Muir-Cochrane E: Medical co-morbidity risk factors and barriers to care for people with schizophrenia. Journal of psychiatric and mental health nursing 2006, 13(4):447-52.

3. Simões do Couto $F$, et al: The characterization of a Portuguese population of outpatients with schizophrenia, and their therapeutical management, in the European context.

4. Teixeira J, et al: Which blood analysis should be requested to patients with schizophrenia when hospitalized for acute psychosis? 17th EPA European Congress of Psychiatry, Lisbon, January 24-28, 2009

doi:10.1186/1744-859X-9-S1-S74

Cite this article as: do Couto: Medical care and long-term treatment of patients with schizophrenia: ethical concerns. Annals of General Psychiatry 2010 9(Suppl 1):S74.

\section{Submit your next manuscript to BioMed Central and take full advantage of: \\ - Convenient online submission \\ - Thorough peer review \\ - No space constraints or color figure charges \\ - Immediate publication on acceptance \\ - Inclusion in PubMed, CAS, Scopus and Google Scholar \\ - Research which is freely available for redistribution \\ Submit your manuscript at www.biomedcentral.com/submit}

